\title{
VAMOS AO CINEMA: PROCEDIMENTOS DE PESQUISA EM DESIGN PARA ACESSIBILIDADE DE PESSOAS CEGAS AO SERVIÇO DE CINEMA
}

Diego Normandi

Universidade de São Paulo

diegonmd@gmail.com

Cibele Taralli Haddad

Universidade de São Paulo

cibeletaralli@gmail.com

Resumo: Este artigo apresenta uma síntese parcial dos resultados de uma pesquisa de Mestrado sobre a inclusão de pessoas cegas ao serviço de cinema, a partir da percepção deste como um sistema complexo, envolvendo diferentes etapas que compõem a experiência, tais como produção, distribuição e exibição de filmes, bem como sua divulgação, processos de compra de ingressos, deslocamento aos ambientes de projeção e interação entre espectadores e o conteúdo audiovisual. O trabalho tomou como base a visão do Design e do Design de Serviços, por acreditar que tais procedimentos colaboram e tem potencial para projetar, desenhar e articular estratégias e stakeholders envolvidos nesse contexto, tendo como princípio a promoção de um serviço de cinema inclusivo.

Palavras-chave: Inclusão, Deficiência Visual, Cinema, Design de Serviços.

\begin{abstract}
This paper presents a partial summary of the results of a Master's research on the inclusion of blind people to the cinema service, from the perception of this as a complex system involving different stages that make up this experience, such as production, distribution and exhibition of movies as well as their divulgation, purchasing tickets process, way to the projection rooms and interaction between spectators and audio-visual information. The work was based on the vision of Design and Service Design, believing that such procedures collaborate and have the potential to design, draw and articulate strategies and stakeholders involved in this context, aiming to promote an inclusive cinema service.
\end{abstract}

Keywords: Inclusion, Visual Disability, Cinema, Service Design. 


\section{INTRODUÇÃO}

A OMS (Organização Mundial de Saúde) identifica que cerca de $10 \%$ da população mundial possui alguma deficiência (SONZA, 2008, p.121). No Brasil, o Instituto Brasileiro de Geografia e Estatística - IBGE aponta que há, no país, uma população de 35 milhões de pessoas com deficiência visual, das quais 6 milhões são cegas (IBGE, 2010). É importante ressaltar que os números relativos à quantidade de pessoas nessas condições ainda são imprecisos, revelando, por vezes, grandes disparidades. Pode-se supor que parte dessa divergência seja oriunda dos diferentes métodos de pesquisas utilizados pelas diversas instituições que estudam e divulgam essas informações ${ }^{1}$. Ainda assim, não se pode subestimar a relevância dos dados divulgados pelo IBGE, que servem de referência para toda a sociedade.

Tomando-se como base os dados do IBGE, é correto afirmar que há no Brasil, um grande número de indivíduos que sofre o descaso da sociedade que elegeu a visão como sentido primordial, e consequentemente, se encontra excluído do convívio nas mais diversas esferas sociais, sem pleno acesso à locomoção nas ruas; às sinalizações de trânsito; às mídias impressas e digitais; ao sistema educacional; às tecnologias de comunicação; à arte e cultura; ao lazer e mesmo à garantia de seus próprios direitos como cidadãos. Na atual "era da informação", o acesso à informação é fundamental para a garantia de direitos e de ascensão social do cidadão. Assim, aqueles que convivem com severa deficiência visual, sobretudo os mais pobres, estão à margem dos benefícios que o avanço das tecnologias digitais possibilitou à boa parte da população. Dessa forma, essa pesquisa revolveu encarar a promoção da inclusão de cegos no universo audiovisual, proposição essa que, muitas vezes, causa estranhamento por parte daqueles que, por qualquer que seja o motivo, se acostumaram com a exclusão daquele público ao convívio com os estímulos proporcionados pela visão.

É necessário apontar que neste trabalho, se compreende o cinema como um importante instrumento de comunicação, informação, educação, cultura, entretenimento e lazer em nossa sociedade, reconhecendo que é grande a influência que obras cinematográficas exercem sobre os costumes de uma sociedade. Acreditase, assim, que a fomentação de políticas de inclusão e de acesso no mercado de cinema pode irradiar a sociedade no sentido da ampliação de medidas inclusivas em outros setores das esferas pública e privada, contribuindo, portanto, para a minimização das barreiras atitudinais no acesso ao pleno convívio social das pessoas com severa deficiência visual.

Por trás da experiência de assistir a um filme em uma sala de cinema, existem diversos processos e atividades que interagem para tornar a atividade possível. Tais procedimentos se estendem desde antes dos filmes chegarem às salas de cinema, em fases de produção, distribuição, publicidade e exibição. Quando em cartaz, outras etapas completam a experiência do espectador, como: publicidade e a exposição de filmes em exibição e próximas estreias; compra dos ingressos, que pode se dar nas bilheterias, sejam elas automáticas ou com o auxílio de um intermediário humano, ou

\footnotetext{
${ }^{1} \mathrm{O}$ Instituto Brasileiro de Geografia e Estatística - IBGE, por exemplo, se utiliza do método de auto-declaração, no qual o indivíduo é questionado se apresenta alguma deficiência e ele responde conforme achar mais apropriado. Tal método, de fato, pode gerar resultados de confiabilidade duvidosa.
} 
por meio de navegação via internet; compra de pipoca, refrigerantes, sucos, doces, salgados e demais guloseimas consumidas no local; deslocamento dos indivíduos até às salas de projeção; percurso interno da entrada até a localização dos assentos previamente escolhidos; identificação de saídas de emergências; sinalização de banheiros; entre outros passos e ações sócio culturais que possam fugir de algum padrão, como o encontro de amigos já dentro das salas ou a compra de produtos relacionados ou não com o filme no ambiente, caso esse possibilite essa prática.

Percebe-se que o serviço de cinema apresenta um conjunto de ações, de interações de múltiplos agentes, de políticas públicas e privadas, de acesso a cultura e educação entre outros aspectos, que o constituem como um sistema complexo, entendendo este termo como “... um sistema composto de muitos elementos, camadas e estruturas, cujas inter-relações condicionam e redefinem continuamente 0 funcionamento do todo" (CARDOSO, 2012, p.24).

Tais procedimentos tem acompanhado a constante evolução da tecnologia e dos serviços inerentes ao processo. Assim, desde sua invenção, a atividade de se assistir a um filme no cinema se tornou um bem sociocultural já reconhecido em nossa sociedade. No entanto, quando se questiona sobre o acesso a esse tipo de experiência por pessoas com deficiência visual, se percebe que as diversas etapas que compõem o processo ainda são inacessíveis a este público. Dessa forma, se avalia que são necessárias novas abordagens e o desenvolvimento de processos que sejam capazes de possibilitar a inclusão de pessoas com deficiência a esse universo de informação, lazer e cultura.

Este trabalho adotou a visão do design dirigido às pessoas cegas e seu acesso ao cinema e universo audiovisual, a partir da pesquisa e experimentação de métodos orientados e centrados no humano, buscando articular os diferentes stakeholders envolvidos no processo, a fim de esboçar uma proposta de serviço de cinema inclusivo. Referenda-se assim o campo de estudos norteado pelo Design de Serviços.

\section{DESENVOLVIMENTO}

\subsection{Questões de pesquisa}

A temática da acessibilidade de pessoas com deficiência visual está bem presente em pesquisas do campo da Linguística. Por tratar-se de uma modalidade de tradução, o processo de audiodescrição $-A D^{2}$ é bem explorado nesse campo de estudo. No que se refere ao desenvolvimento de produtos digitais para esse público, a área de Tecnologia da Informação - TI conta com diversas pesquisas e produtos desenvolvidos, sobretudo na área de Informática Educativa. É possível encontrar na internet diversos artigos e experimentos envolvendo a temática. Contudo, ainda há uma lacuna quando o tema é centrado no desenvolvimento de serviços. No campo do Design, por exemplo, há poucas pesquisas que tratem a questão da acessibilidade e da inclusão sob a ótica dos serviços, mais especificamente do Design de Serviços.

\footnotetext{
2 Trata-se de uma modalidade de tradução intersemiótica (JAKOBSON, 1995) que objetiva a apresentação, via faixa sonora, de signos visuais em qualquer apresentação que use a visão como forma de aquisição de informação. Esse processo permite a percepção do que é apresentado através de estímulos audiovisuais.
} 
Dessa perspectiva, orientou-se a pesquisa à resposta da seguinte questão: "no que se refere ao acesso de pessoas com severa deficiência visual a salas de cinema (em toda a complexidade dessa experiência), quais dificuldades enfrentadas por esse público podem ser contornadas ou minimizadas, na apropriação dos conteúdos socioculturais das mensagens audiovisuais, e no uso das condições de acessibilidade física, emocional e informacional, a fim de lhes proporcionar uma experiência equiparável às já experimentadas por aqueles que não têm deficiência visual, por meio de abordagem exploratória e interdisciplinar, com foco na inclusão, e a partir de métodos de Design e de Design de Serviços?".

A partir desta grande pergunta, foram formuladas subquestões, a fim de se obter um conjunto de respostas mais objetivas e passíveis de inter-relacionamentos, facilitando tanto a exploração do tema como a coleta e a análise de dados. Iniciou-se com o questionamento sobre quais dificuldades um cego pode enfrentar no processo que envolve a experiência de assistir a um filme no cinema. A partir daí, buscou-se relacionar as diferentes ferramentas assistivas, que hoje já estão disponíveis aos usuários cegos e à sociedade, no sentido de contribuir com o acesso e minimizar as barreiras encontradas para a inclusão desse público nas salas de cinema, bem como aos procedimentos anteriores a este momento, como a publicidade e divulgação de filmes em cartaz, o deslocamento até os espaços de exibição, a compra de ingressos etc. Na sequência, se questionou sobre o que rege a legislação brasileira quanto aos direitos da pessoa com deficiência visual e os deveres e obrigações que as instituições, entidades e espaços públicos e privados devem seguir, no que diz respeito à inclusão daquele público aos conteúdos culturais, educativos e publicitários, bem como aos ambientes físicos e virtuais. Da mesma forma, foram pesquisados processos de fiscalização e execução daquelas leis e normas. No que diz respeito à tradução dos conteúdos audiovisuais em uma linguagem acessível ao público cego, considerou-se a Audiodescrição como referência e método eficaz de comunicação. Assim, questionouse como se realiza a audiodescrição de filmes, quais os custos envolvidos no processo, quanto tempo é necessário para realizá-la, e, por fim, quantas pessoas são necessárias para a realização desse tipo de procedimento. Finalmente, a pesquisa orientou suas questões para os métodos de Design, buscando apontar quais deles poderiam ser aplicados para a obtenção de dados e formulação de parâmetros que possibilitem a inclusão de cegos na experimentação do serviço de cinema em toda sua complexidade, bem como buscou avaliar se uma abordagem exploratória, holística, interdisciplinar e colaborativa poderia contribuir de forma mais eficiente na definição de modelos capazes de permitir ou, pelo menos, facilitar a inclusão de cegos em salas de cinema.

\subsection{Processos de Pesquisa}

Esse artigo faz parte de uma investigação maior e complexa, que envolveu um grande ciclo de atividades, planejamento e execução de ações. Contextualizou-se a pesquisa no território brasileiro, tomando como base experimentos locais, profissionais desse país e a legislação vigente. A pesquisa adotou abordagem qualitativa e enfoque exploratório e descritivo, auxiliada por métodos do campo de conhecimentos em Design, com o objetivo de aprofundar estudos e realizar analises sobre a temática do acesso e da inclusão de pessoas com deficiência visual em salas de cinema, a partir do levantamento de dados de oferta e de demandas, e da busca de opiniões dos diferentes stakeholders envolvidos, estabelecendo diálogos, e trazendo 
uma discussão inter-relacionada entre meios, agentes e estratégias inerentes à área do Design de Serviços.

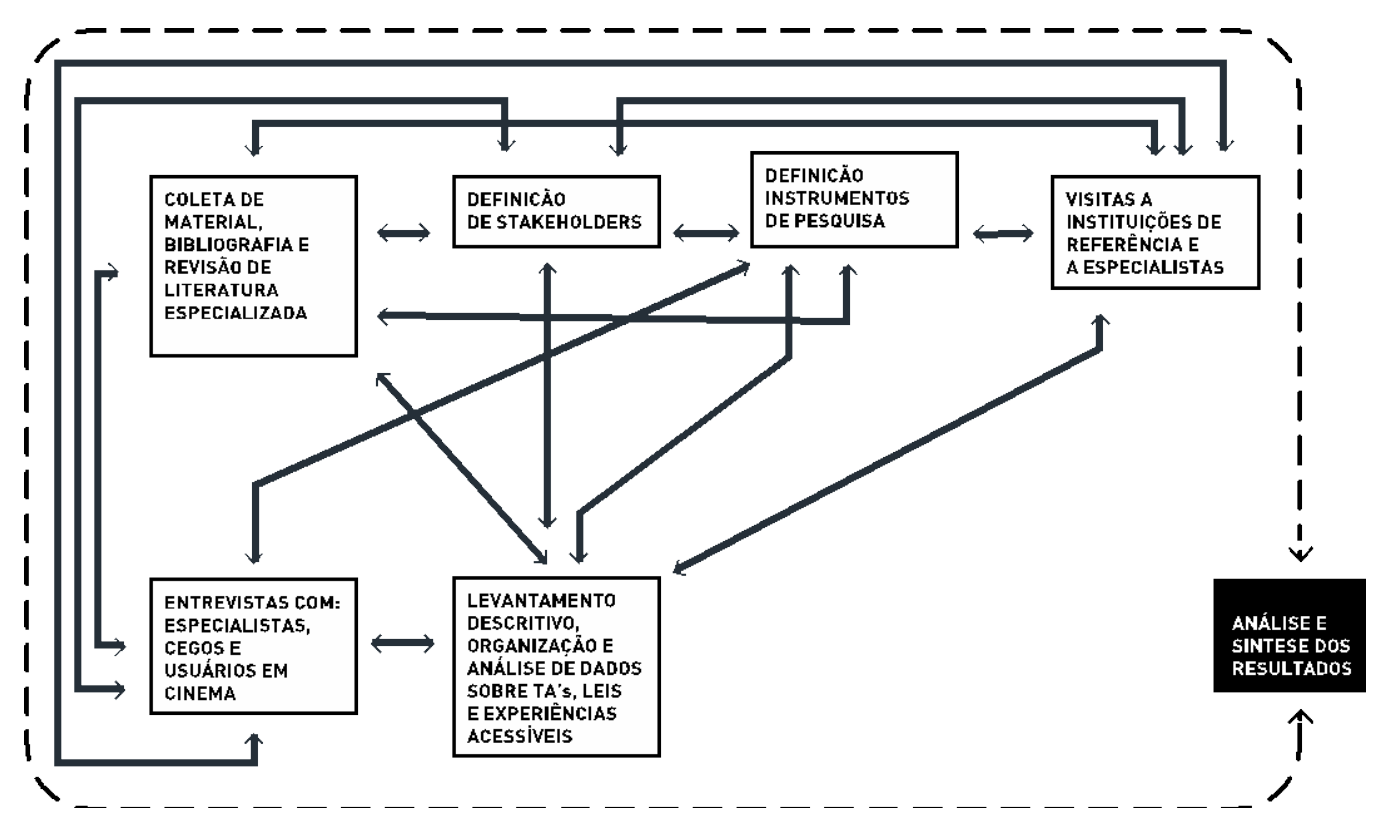

Figura 1 - Procedimentos de Pesquisa

Fonte: Elaborado pelo autor, com base na pesquisa realizada.

Para as questões de conceituação e levantamento dos estudos já realizados neste e em temas correlatos, executou-se uma ampla revisão da literatura nas diversas áreas que compõem a pesquisa - Acessibilidade, Legislação Brasileira, Tecnologias Assistivas, Design, Design de Serviços e Cinema, buscando, sempre que possível, aproximar os diferentes campos.

Considera-se que há grande quantidade de fatores e de pessoas que interferem na possibilidade de oferecer um serviço de cinema capaz de incluir pessoas com severa deficiência visual, e assim buscaram-se, por meio de diferentes modalidades de entrevistas e de utilização de técnicas pertinentes às áreas do Design e do Design de Serviços, explorar processos, hábitos, costumes, situações, instrumentos, tecnologias, leis, normas, dificuldades e facilidades que envolvam a possibilidade de oferecer uma experiência equiparável de serviço de cinema a pessoas com deficiência visual, em moldes de operação e qualidade as já oferecidas àqueles sem deficiência visual. Dessa forma, exploraram-se, também, práticas comerciais de serviços oferecidos pela cadeia de entidades que envolvem a produção, a distribuição e a exibição de filmes nos espaços de apresentação.

A amostra de público e de profissionais investigados foi delimitada a partir do processo de definição de stakeholders que atuam no e para o serviço de cinema.

Aliado ao levantamento de dados primários e secundários buscou-se, por meio de visitas, entrevistas, gravações de áudio, vídeos e fotografias, uma imersão na experiência de pessoas e instituições públicas e privadas consideradas referência na acessibilidade do público em questão. Dentre as instituições: Iguale; Mais Diferenças; Laramara; Fundação Dorina Nowill; Pinacoteca do Estado de São Paulo; Memorial da Inclusão; Centro Cultural São Paulo; Instituto Benjamin Constant; LEAD (Grupo Legendagem e Audiodescrição) e Gráfica Braille do Governo do Estado do Ceará. 
No tocante ao mercado cinematográfico, foram escolhidos profissionais e empresas que contribuem com a estrutura desse setor: cineastas, distribuidores e exibidores.

Assim, os procedimentos metodológicos foram divididos em sete etapas, sem sequência cronológica. As diferentes etapas ocorreram concomitantemente, ou progrediram independente da conclusão das anteriores (ver tabela a seguir).

\subsection{Referenciais Teóricos}

Para o desenvolvimento da pesquisa, o levantamento de dados secundários foi oriundo de diferentes campos do conhecimento, tais como Serviços, Design e Design de Serviços, Legislação Brasileira, Acessibilidade e Tecnologias Assistivas.

Dentre os principais conceitos trabalhados pode-se apontar:

1. Acessibilidade como "condição para utilização, com segurança $e$ autonomia, total ou assistida, dos espaços, mobiliários e equipamentos urbanos, das edificações, dos serviços de transporte e dos dispositivos, sistemas e meios de comunicação e informação, por pessoa portadora de deficiência ou com mobilidade reduzida" (BRASIL, 2014).

2. Tecnologias Assistivas ou TA's como ferramentas que permitem a transposição de barreiras e possibilitam que pessoas com deficiência possam conviver em sociedade e desfrutar a vida da maneira mais natural possível. Outra definição importante é "todo e qualquer item, equipamento, produto ou sistema que contribua com o desenvolvimento das potencialidades de indivíduos com limitações físicas, sensoriais, cognitivas, motoras, dentre outras restrições ou disfunções que caracterizam uma deficiência ou incapacidade de qualquer natureza". (VIVARTA \& VEET, 2003).

3. Sobre Serviços, dentre outras concepções, apoiou-se nas ideias de Lovelock e Wright (2001), compreendendo os serviços como fenômenos relacionados intimamente a propostas intangíveis, por mais que se considerem estreitas as relações de determinado serviço a algum produto tátil e físico, no sentido de que o que define a qualidade desse serviço não se restringe a um benefício palpável.

4. Se compreende o Design de Serviços a partir da concepção de Moritz (2005), quando propõe que o profissional deste campo é capaz de projetar a experiência de um serviço por parte do usuário, e que para tanto deve considerar toda a complexidade que envolve o processo, no qual é preciso analisar as diferentes etapas que configuram a jornada do cliente. Nesse sentido, o designer de serviços seria o responsável por reger uma equipe multidisciplinar capaz de projetar, planejar e viabilizar a jornada ideal do cliente no serviço, a partir da identificação dos principais pontos de contato entre cliente e serviço, visando sempre o melhor atendimento às necessidades desse consumidor

5. Sobre a concepção de Design, buscaram-se autores que colocam questões orientadas ao social e às pessoas, seguindo a crítica de Gui Bonsiepe quando afirma que o termo Design passou a ter significado "multiuso", se distanciando cada vez mais da ideia de "solução inteligente de problemas" $e$ se aproximou do efêmero, da moda, do obsoletismo rápido (...) da 
glamourização do mundo dos objetos. (BONSIEPE, 2011, p.18). Assim, Philip Agre (2000), citado por Krippendorf (2000), diz que o Design saiu do domínio restrito do designer e contaminou a sociedade, se apresentando como um conceito de estilo de vida. Com olhar mais otimista, também se apresentou Krippendorf, que aponta que durante sua evolução, o design migrou o foco da criação de artefatos para o pensamento relacionado intrinsecamente ao convívio social, no que definiu como "Human-Centered Design", que aqui se traduz como design centrado no humano (KRIPPENDORF, 2000). Essa filosofia é endossada por Sato (2000), que a segmenta em três grandes áreas: Human Science, Ciências Sociais e Tecnologia. Em síntese, pode-se afirmar houve a passagem do design focado no produto ou no objeto para o design focado no humano, e na sociedade. Dessa aproximação entre design e o ser humano, se busca orientar conceitos desta área como processo orientado ao bem-estar social, retomando as concepções de Victor Papanek (1983), que defendia o design não apenas voltado para as demandas ou situações do mercado e do lucro, mas centrado na melhoria das condições de vida do ser humano e no próprio futuro da humanidade. Em outra abordagem, Donald Norman (2006) afirma que o Design não pode se limitar a desenvolver produtos voltados à maioria da população, considerando não existir um padrão universal que equipare toda a diversidade humana; e Nigel Whiteley (1993), que faz duras críticas ao sistema capitalista ao tentar buscar soluções e apontar caminhos para que o Design possa atuar na sociedade da forma mais inclusiva possível. O mesmo autor chama o Design para voltar suas atividades ao setor social, sobretudo na atuação em conjunto com o ideal público. É o que o autor vem chamar de "Design Valorizado":

"O design valorizado é, em suma, aquele que possui uma compreensão crítica dos valores que fundamentam o design (...) disposto a defender ideias sociais e culturais mais elevados do que o consumismo a curto prazo, com a sua bagagem obrigatória de degradação ambiental. $O$ designer valorizado deve enxergar no design o potencial para contribuir com uma qualidade de vida melhor e mais sustentável“ (WHITELEY, 1998, p.74).

6. No tocante ao que a Legislação Brasileira rege quanto à acessibilidade de pessoas com deficiência, se destaca o artigo 50 da Constituição Federal (1988), que estabelece que "todos são iguais perante a lei, sem distinção de qualquer natureza", $\theta$ que se constata ser ainda uma-bela utopia para parte da população, sobretudo àqueles com deficiência visual, que enfrentam diariamente uma série de barreiras físicas, comportamentais, atitudinais, entre outras, que impedem seu acesso à vida social, pública e privada. A partir desse entendimento, foi realizado um amplo levantamento do conjunto de Leis brasileiras voltadas à minimização daquelas barreiras, tendo em vista a inclusão do público com deficiência à plenitude de convívio social.

\subsection{Instrumentos de Pesquisa}

A partir do conjunto de questões e objetivos traçados e tendo por base métodos de trabalho oriundos das Ciências Sociais Aplicadas orientados e dirigidos ao Design e Design de Serviços, optou-se pelos seguintes instrumentos de pesquisa: (1) 
Construção de Mapa de Stakeholders; (2) Visitas a Instituições; (3) Entrevistas Contextuais; (4) Criação de Personas; (5) Indução de Relatos; (6) Construção de Mapas de Expectativas; (7) Entrevistas Individuais e Exploratórias. Tais instrumentos tomaram também como base dois importantes referenciais, como o livro "Isto é Design Thinking de Serviços" (STICKDORN E SCHNEIDER, 2014) e o site "designing with people" (http://designingwithpeople.rca.ac.uk/), oferecido pelo do Royal College of Art, que apresenta um amplo leque de modelos e métodos de pesquisa em Design.

À exceção das visitas a instituições, todos os instrumentos de pesquisa foram formularizados e estruturados a fim de colher dados primários. As visitas foram fundamentais para aprofundar os conhecimentos relacionados aos dados secundários, bem como para estabelecer um contato mais próximo a determinados stakeholders.

A seguir, são apresentados os instrumentos e seu método de utilização:

\section{Mapa de Stakeholder:}

Conceito: Consiste em uma representação visual (ilustração, desenho, fotográfica etc) do conjunto de indivíduos que se relacionam, de alguma forma, a um processo, fenômeno, ou evento pesquisado. A esses sujeitos, atribuímos a expressão stakeholders (STICKDORN e SCHNEIDER, 2014).

Utilização: O desenho do mapa levou em consideração o levantamento de situações relacionadas ao oferecimento de um serviço inclusivo de cinema. Foram identificados indivíduos que interferem ou poderiam interferir com o objetivo, de forma positiva, neutra ou negativa. A seguir é apresentado o mapa construído destaque-se os elementos em cor mais escura, que compõem os stakeholders selecionados no estudo.

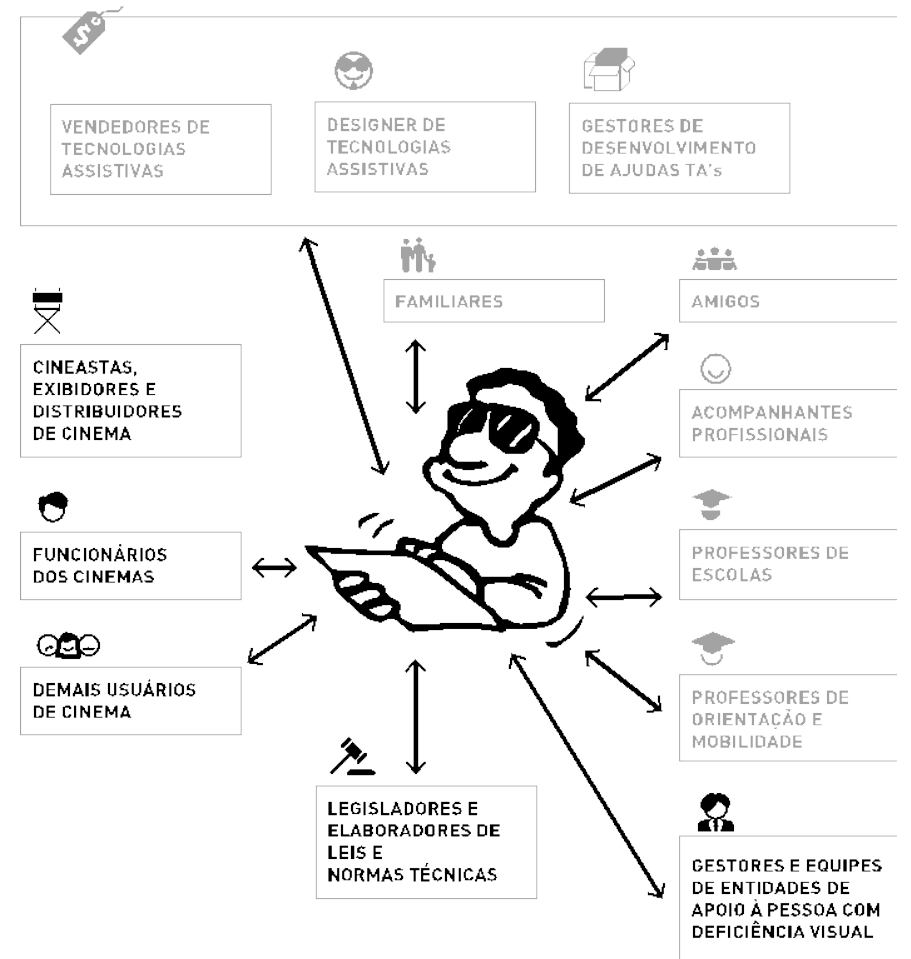

Figura 2 - Mapa de Stakeholders

Fonte: Elaborado pelo autor, com base na pesquisa realizada 


\section{Entrevistas Contextuais:}

Conceito: Técnica etnográfica que consiste em entrevistas realizadas no ambiente onde se dá o serviço, o processo ou fenômeno estudado (STICKDORN e SCHNEIDER, 2014). Para realizá-la é necessária a presença dos pesquisadores no local, munido de conhecimento sobre as questões analisáveis, bem como de equipamentos que permitam a captação das informações, que podem ser canetas e papéis, máquinas fotográficas e de vídeo ou gravadores de áudio.

Utilização: Entrevistas realizadas em espaços de cinema, com espectadores à espera do início de suas sessões. A técnica foi selecionada para que os entrevistados tenham mais facilidade em lembrar-se das questões que lhes são apresentadas. Previamente, foi formularizada uma ficha de entrevista com questões referentes aos hábitos e preferências do usuário no que se refere à sua ida ao cinema e a seus procedimentos de escolha de filmes, compra de ingressos, deslocamento até a sala de cinema, entre outros. As entrevistas foram marcadas na ficha e gravadas via áudio. Os dados obtidos com esse procedimento foram tomados como base para construção de personas sem deficiência (ver a seguir).

\section{Criação de Personas:}

Conceito: Procedimento que consiste na criação de personagens - daí o nome personas, com características físicas ou comportamentais particulares. Para Stickdorn e Schneider (2014), são perfis fictícios que servem para representar um grupo específico de pessoas, com base em interesses (ou condições) comuns.

Utilização: Foram criadas quatro personas, duas cegas e duas sem deficiência visual. Conforme apresentado no item anterior, as personas não cegas foram definidas tendo por base os resultados das entrevistas contextuais: Maria - que representava o perfil da maioria dos entrevistados; e Cíntia, caracterizando os entrevistados considerados cinéfilos, mais especificamente, os indivíduos que frequentam cinemas mais de duas vezes por semana. Para representar as personas cegas, tomaram-se como base os dados obtidos com as entrevistas exploratórias (ver a seguir). Assim, desenharam-se duas personas com diferentes características, uma cega, mais conectada às experiências culturais públicas ou privada que a sociedade oferece Lívia, e outro mais contido e temeroso - Caio, que evita lançar-se a encarar eventos que não oferecem condições adequadas de acesso.

\section{Entrevistas com Cegos (Individuais e Exploratórias) e com Especialistas:}

Conceito: Segundo Meuser e Nagel apud Flick (2009), estas entrevistas se destacam por ter menos interesse com a pessoa do sujeito entrevistado, mas sim com o que o faz especialista em determinado assunto. Os entrevistados enquadrados nessa tipologia não representam a si mesmo em uma pesquisa, mas a um grupo específico do qual ele faz parte. No caso das pesquisas exploratórias, para Quivy e Campenhoudt (1998, p.69) "Leituras e entrevistas exploratórias devem ajudar a constituir a problemática da investigação. (...) as entrevistas servem para descobrir os aspectos a ter em conta e alargam ou ractificam o campo de investigação das leituras".

Utilização: Optou-se por fazer entrevistas com especialistas diretamente relacionados às áreas do cinema; da tradução intersemiótica audiovisual (ou da audiodescrição) e com indivíduos cegos. Foram selecionados dois audiodescritores, dois cineastas, dois exibidores de filmes em cinema e dois distribuidores de filmes. 
Para cada grupo, foi desenvolvida uma ficha específica de entrevista, com questões exploratórias, cujos resultados serviram para articular as relações entre os diferentes profissionais, bem como estabelecer possibilidades de articulações em vistas de uma proposta de cinema inclusivo. No que se refere às entrevistas com pessoas cegas, entrevistou-se, orientados por um questionário exploratório, uma série de indivíduos.

\section{Indução de Relatos}

Conceito: Trata-se de um procedimento de coleta, nomeado pelo autor, para a captação de informações baseado na técnica tradicionalmente conhecida como storytelling. Segundo Stickdorn e Schneider (2014), o storytelling é um modelo para compartilhamento de insights, a partir da construção de narrativas. Katja Battarbee (2003) ressalta que o método facilita e amplia a compreensão sobre a relação entre usuário e produtos, sobretudo quando seu desenvolvimento conta com a utilização de imagens. Um exemplo que a autora traz é o álbum de fotografias, que pode servir como uma ferramenta de auxílio para recordação de fatos e, consequentemente, a elaboração de uma narrativa mais fidedigna. Além disso, pode-se deduzir, por exemplo, que o storytelling é capaz de revelar facetas de utilização de artefatos ou de experiências não imaginadas a quem os projetou.

Utilização: Os entrevistados - todos cegos, foram contatados previamente e apresentados aos objetivos de pesquisa. Posteriormente, foi enviado um modelo de roteiro, via e-mail, para que cada indivíduo descrevesse suas percepções, facilidades e dificuldades percebidas na utilização dos serviços de cinema ou na interação com outros métodos de fruição audiovisual, como filmes em TV, DVD's, VHS, entre outros. A proposta visou a participação mínima do pesquisador, que apenas orientou e esclareceu dúvidas no contado inicial. Esperava-se que os próprios entrevistados ficassem à vontade para descrever suas experiências da forma mais livre possível.

\section{Mapa de Expectativas}

Conceito: Consiste no mapeamento de expectativas de usuários na utilização de determinado serviço (STICKDORN e SCHNEIDER, 2014). Pode ser elaborado em formatos variados como de imagens, vídeos, fotografias ou documentado por escrito.

Utilização: Como no caso da Indução de Relatos, o procedimento foi realizado de maneira online, por meio da troca de e-mails. Aproveitou-se do mesmo contexto e orientação realizada para a Indução de Relatos. A construção do mapa foi desenvolvida pelos stakeholders cegos por meio da escrita de textos enviados por e-mail.

O diagrama a seguir ilustra a relação entre os diferentes instrumentos de pesquisas utilizados na pesquisa. 


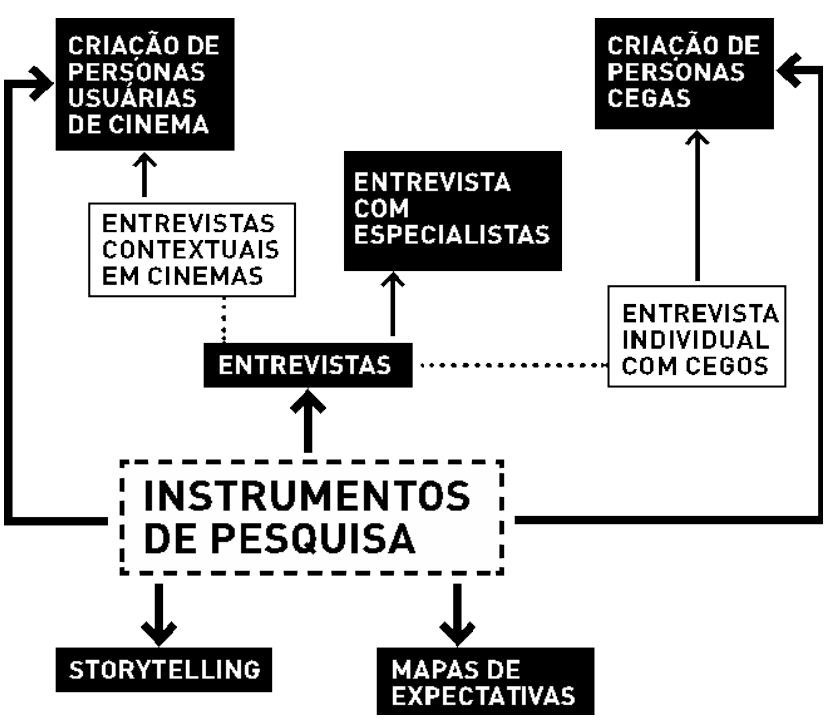

Figura 3 - Instrumentos de pesquisa

Fonte: Elaborado pelo autor, com base na pesquisa realizada

\section{CONCLUSÃO}

A partir do levantamento de dados secundários, foi possível constatar que, no Brasil, muitas iniciativas surgiram mirando o acesso de pessoas com deficiência visual em salas de cinema, como o caso da normativa 116, de 2014, proposta pela Agência Nacional de Cinema - Ancine, bem como à criação se um grupo para a discussão da temática e desenvolvimento de um guia específico para a garantia de acessibilidade de pessoas com deficiência em salas de cinema. Contudo, se percebe que grande parte das ações voltadas a inclusão de pessoas cegas em cinema concentram-se em áreas de pesquisa da Linguística e da Tradução, com foco nos processos de tradução intersemiótica e na recepção do espectador, o que permite concluir que é necessária uma abordagem do tema a partir de uma perspectiva mais abrangente, interrelacionada e multidisciplinar envolvendo todos os agentes e ações intervenientes neste tema. Acredita-se, portanto, que não se deve reduzir as discussões àqueles campos do conhecimento. Reforça-se, contudo, que métodos de Design de Serviços e de Design Centrado no Usuário podem ser ferramentas essenciais na garantia do acesso e da inclusão de pessoas com deficiência nas mais variadas situações.

Percebe-se que tem sido forte a participação pública no setor de cinema. Ao mesmo tempo, pode-se afirmar que a legislação brasileira no tocante à acessibilidade demonstrou grande preocupação no que diz respeito ao oferecimento de condições físicas e de locomoção para pessoas com deficiência: rampas, pisos táteis e elevadores são exemplos. No entanto, quando se necessita de procedimentos relacionados ao oferecimento de serviços que demandem ações "extra", deslocamentos nas cidades, condições de adaptação ou projeto de espaços adequados, atividades de bens ou serviços intangíveis como a seleção de filme ou a compra de ingresso com segurança e autonomia do usuário, se percebe que não há orientações que regulem essa questão.

No que concerne à utilização de métodos de Design de Serviços como ferramenta articuladora dos diversos processos e stakeholders que envolvem a proposição de um modelo de cinema inclusivo, pode-se afirmar que se apresentaram 
com grande potencial, no entanto, sentiu-se a necessidade da adaptação ou criação de novos métodos de pesquisa e co-criação de resultados, haja vista que grande parte das ferramentas encontradas na literatura do Design e do Design de Serviços se mostrou inacessível a indivíduos com severa deficiência visual. A criação do método "Indução de Relatos", inspirado no método Storytelling, apresentado anteriormente, demonstra que é possível propor novas possibilidades a partir de conceitos já desenvolvidos. Buscou-se, durante a pesquisa, realizar o acompanhamento de indivíduos em situações de cinema, pois surgiram algumas possibilidades nas cidades de São Paulo e Rio de Janeiro. No entanto, as experiências ocorridas pecaram por não apresentarem orientação inclusiva, mas exclusivas, haja visto que se contiveram em proporcionar a utilização de ferramentas com audiodescrição. Na capital fluminense, por exemplo, um edital de cultura buscou promover a acesso de pessoas com deficiência visual e auditiva em salas de cinema, por meio do financiamento da instalação de recursos tecnológicos. Tal projeto (de 2014) entretanto, até o início de 2016 não apresentava qualquer programação acessível a esse público.

\section{REFERÊNCIAS}

AGÊNCIA NACIONAL DE CINEMA - Ancine. Disponível na internet por http em: $<$ www.ancine.gov.br>. Acesso em 20 jan. 2016

BATTARBEE, Katja. Co-experience: Understanding user experiences in social interaction. 2004. 216p. Academic dissertation. University of Art and Design Helsinki, Helsinki, 2004.

BONSIEPE, Gui. Design, Cultura e Sociedade. São Paulo: Blucher, 2011.

BRASIL. Constituição da República Federativa do Brasil. Brasília: Imprensa Oficial, 1988. Portaria no 188.

CARDOSO, Rafael. Design para um mundo complexo. São Paulo: Cosac Naify, 2012.

FLICK, Uwe. Introdução à Pesquisa Qualitativa. Porto Alegre: Artmed, 2009.

IBGE - Instituto Brasileiro de Geografia e Estatística. Censo 2010. Disponível em: http: http://www.censo2010.ibge.gov.br/. Acesso em: 12 de agosto de 2012.

JAKOBSON, R. Linguística e comunicação. São Paulo: Cultrix, 1995.

KRIPPENDORFF, Klaus. Propositions of Human-centeredness: A Philosophy for Design. In DURLING, David; FRIEDMAN, Ken (Org.), Doctoral Education in Design: Foundations for the Future. Staffordshire (UK): Staffordshire University Press, 2000.

LOVELOCK, C.; WRIGHT, L. Serviço: marketing e gestão. São Paulo: Saraiva, 2001.

MORITZ, S. Service Design: Pratical Access to an evolving field.Faculty of Cultural Science. Cologne: Köln International School of Design, University of Applied Sciences Cologne, 2005.

NORMANDI, Diego. Design para acessibilidade: inclusão de pessoas com deficiência visual ao serviço de cinema. 2016. 356 f. Dissertação (mestrado) - Universidade de São Paulo, Pós-Graduação em Arquitetura e Urbanismo. 
PAPANEK, Victor. Design for the real world: human ecology and social change. Londres: Paladin, 1974.

QUIVY, R. e CAMPENHOUDT, L. V. Manual de investigação em ciências sociais. Lisboa: Gradiva, 1998.

SATO, Keiichi. Constructing Knowledge of Design, part 1: understanding concepts in design research. In DURLING, David; FRIEDMAN, Ken (Org.), Doctoral Education in Design: Foundations for the Future. Staffordshire (UK): Staffordshire University Press, 2000.

SONZA, Andréa Poletto. Ambientes virtuais acessíveis sob a perspectivas de usuários com limitação visual. 2003. 313 f. Tese (doutorado) - Universidade Federal do Rio Grande do Sul, Centro Interdisciplinar de Novas Tecnologias.

STICKDORN, Mark. Isto é Design Thinking de Serviços. Porto Alegre: Bookman, 2014.

VIVARTA, VEET. Mídia e deficiência. Brasília: Andi; Fundação Banco do Brasil, 2003.

WHITELEY, N. O Designer valorizado. Arcos, Rio de Janeiro, v. 1, n.único, p. 63-75, 1998. 